\title{
Re-attachment of Subgingivally Oblique Fractured Central Incisor Using a Fiber Post
}

Necdet Adanira

Evren $\mathrm{Ok}^{\mathrm{b}}$

Yesim Erdekc

\section{ABSTRACT}

This case report presents a 32 year old male with an oblique fractured maxillary right central incisor. The procedure used to repair the fracture included flap surgery with an intrasulcular incision and endodontic treatment. The root canal was filled with a root canal sealer and gutta-percha. After root canal obturation, fragments were luted with composite resin using a glass fibers post. After 12 months, clinical and radiographic examinations showed a stable reattachment of the fragments, good aesthetics and periodontal health. (Eur J Dent 2008;2:138-141)

Key words: Dental trauma; Teeth fractures; Fiber post; Resin composite; Fragment reattachment.

\section{INTRODUCTION}

The treatment of complicated crown-root fractures in many cases is compromised by tooth fractures that are well below the gingival margin

- assistant Professor, Department of Endodontics, Faculty of Dentistry, S. Demirel University, Isparta, Turkey.

b Doctorate Student, Department of Endodontics, Faculty of Dentistry, S. Demirel University, Isparta, Turkey.

c Research Assistant, Department of Periodontology, Faculty of Dentistry, S. Demirel University, Isparta, Turkey.

- Corresponding author: Dr. Necdet ADANIR S. Demirel Universitesi, Dishekimligi Fakultesi, Endodonti AD., Dogu Kampusu, 32060 Isparta / TURKIYE Phone: + 902462113287 Fax: + 902462370607 E-mail: necdet@dishek.sdu.edu.tr

or bone. After root canal obturation, proper isolation for a dry operation field is critical for successful restoration of traumatized teeth. In this respect, a wide range of treatment options have been advocated for traumatic permanent teeth include;

1. orthodontic extrusion ${ }^{1}$

2. osteotomy / osteoplasty ${ }^{2}$

3. intentional replantation ${ }^{3}$

4. re-attachment of fragments ${ }^{4}$

5. extraction.

Re-attachment of a tooth fragment should be preferable to restoring fractured teeth. There are several advantages in this treatment such as obtaining esthetic in a single appointment, being more conservative procedure, obtaining healthy periodontal attachment and it maintains the 
original tooth contours and translucence as the patient's own. 5,6

The present case report describes the reattachment of an original tooth fragment using a glass fiber post.

\section{CASE REPORT}

A 32-year-old male patient was referred to the Endodontic Clinic of the Faculty of Dentistry, S. Demirel University, with the complaint of a fractured right maxillary incisor tooth because of a trauma. The patient's medical history was non-contributory. The patient related pain during breathing and bleeding through the line of fracture (Figure 1). The clinical and radiographic examinations showed an oblique crown-root fracture in the maxillary right central incisor involved the enamel-dentin junction and extended from buccal to the palatal aspect subgingivally. Bilaterally maxillary canines were impacted.

After anesthesia, mobile coronal tooth

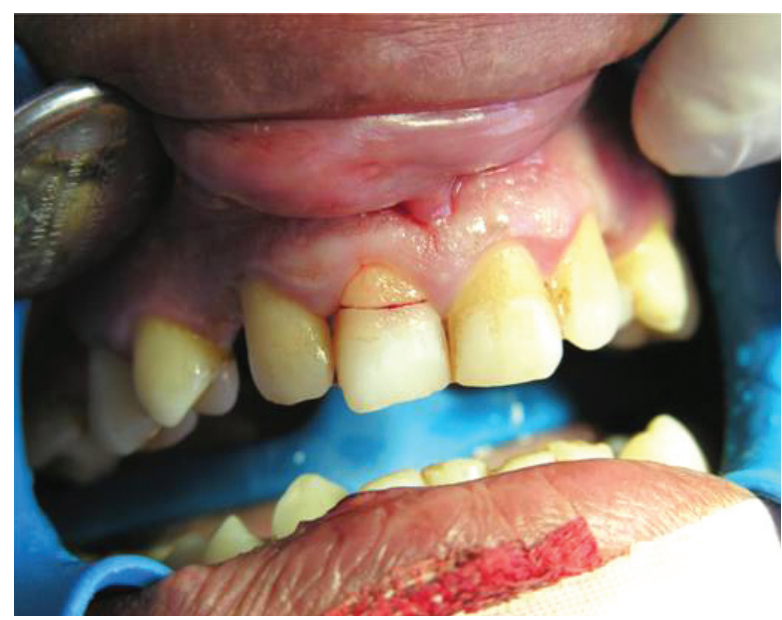

Figure 1. Fractured maxillary right central incisor.

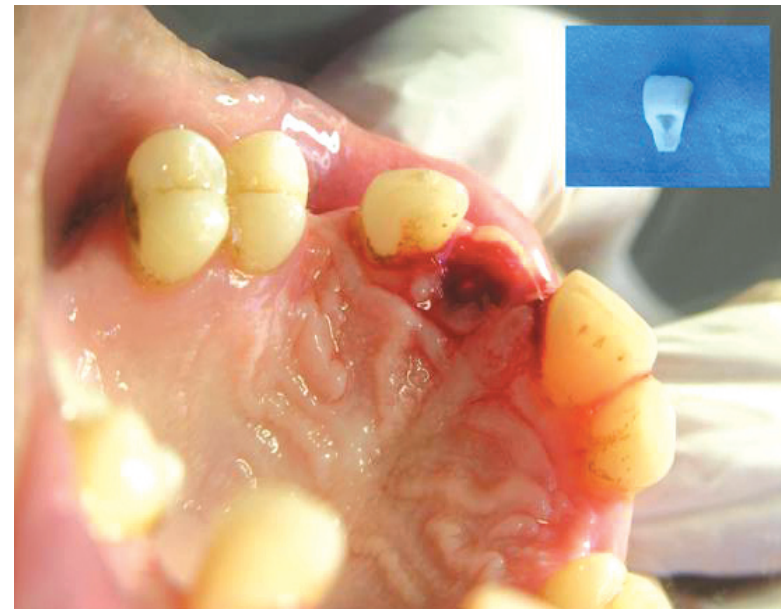

Figure 2. Intraoral view showing the maxillary right central incisor after the crown portion was removed. fragment was removed (Figure 2). Root canal pulp extirpation and canal preparation was performed using the standard step-back method. The prepared teeth were dried with paper-points (Dentsply Maillefer, Tulsa, OK) and filled with laterally condensed gutta-percha (Diadent Group International Inc., Chongju, Koreal and Sealapex (Kerr, Manufacturing Co., Romulus, MI) root canal sealer. After sealer set, the gutta-percha was partially removed from the root canal using heated instrument, leaving $5 \mathrm{~mm}$ of the filling material at the apex to maintain a good sealing. A post hole within root and coronal fragment was prepared using a drill recommended by manufacturer (Carbotech, Ganges, France). A glass fiber post (Snowpost, Carbotech, Ganges, France) was cemented within root canal with dual adhesive cement (Variolink II, Ivoclar Vivadent, Schaan, Liechtenstein). After taking his consent, full thickness buccolingual mucoperiostal flap was raised with an intrasulcular incision (Figure3). After all debris on the fractured root surface was scaled, washed away with sterile serum physiologic and dried. A primer (Kuraray Co. Ltd, Osaka, Japan) was applied onto the fractured surfaces of the tooth fragments for 20 second. Volatile ingredients were evaporated with mild air stream. Clearfil SE (Kuraray Co. Ltd, Osaka, Japan) bonding agent was applied to the primed surfaces of the fragments and light cured for 10 second. The fragments were reattached with a composite resin (Clearfil AP-X, Kuraray Co. Ltd, Osaka, Japan). The excess resin was removed with an excavator and the crown was light cured for 40 seconds from both buccal and

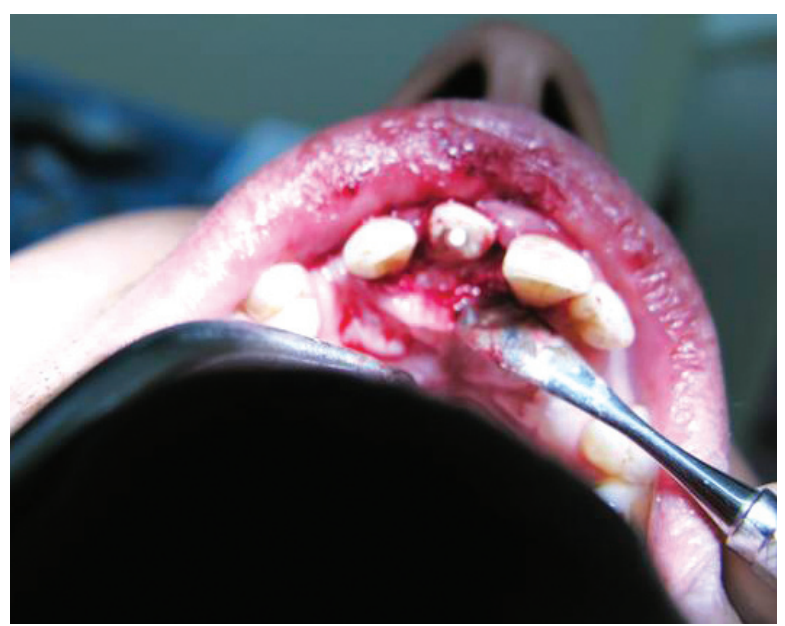

Figure 3. Mucoperiostal flap surgery. 
palatal aspects. Final polishing of the crownroot interface was made with ultrafine diamond burs and polishing disks. After all, the flaps were sutured (Figure 4). One week later, the sutures were removed and clinical examination was revealed proper healing (Figure 5).

One month later, the clinical and radiographic

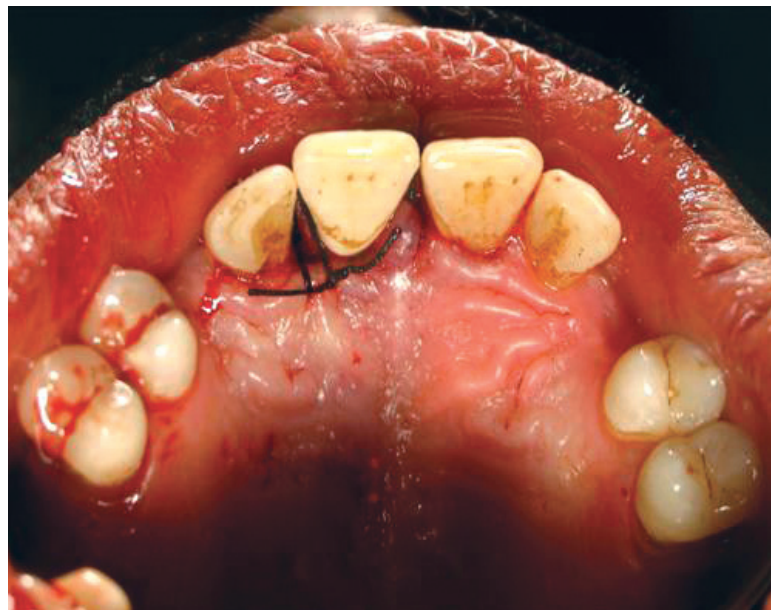

Figure 4. Intraoral view after the flap surgery.

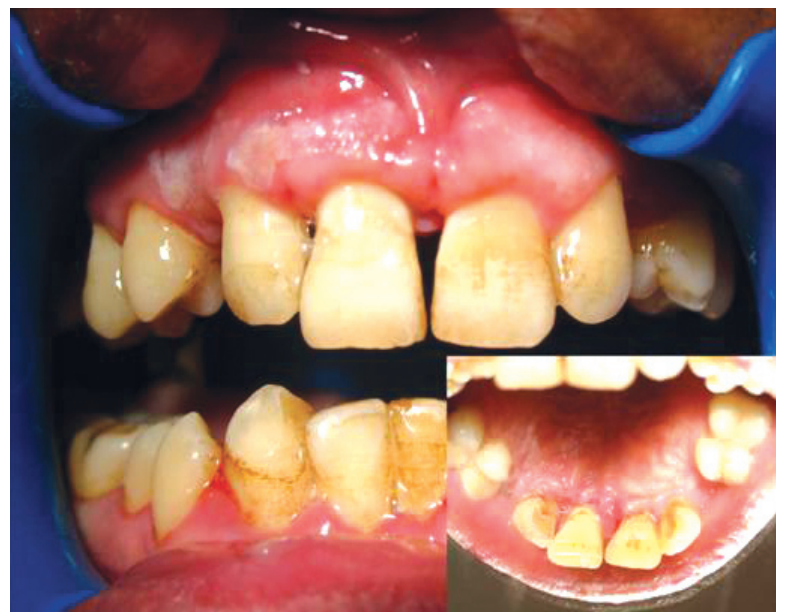

Figure 5. Intraoral view after sutures was removed.

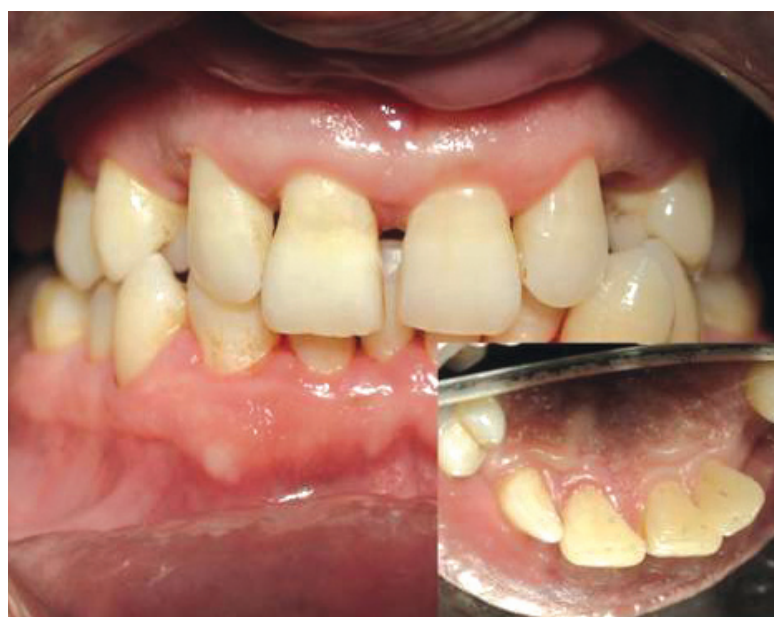

Figure 7. Tooth at 12 month recall. examinations revealed a stable reattachment of the crown fragment (Figure 6). After 12 months, clinical and radiographic examinations showed a stable reattachment of the fragments, good aesthetics and periodontal health (Figures 7 and 8).

\section{DISCUSSION}

The present case report described that tooth fragment reattachment is an alternative to composite resin build-up for restoring esthetics and function of oblique fractured teeth.

Up to date, a lot of different approaches were proposed for treatment of fractured teeth depending on location of the fracture. ${ }^{7}$ One of the options for managing coronal tooth fractures is the reattachment of the dental fragment. ${ }^{4}$ Re-attachment of fragments offers a good esthetic, less time-consuming and cost-effective restorative option. Contemporary resin adhesives and resin post systems that allow strong durable

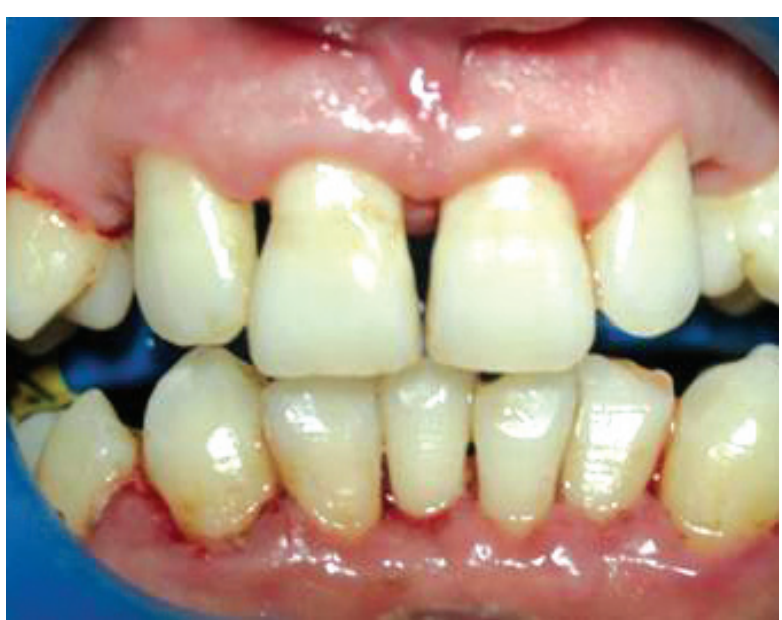

Figure 6. Clinical examination after one month.

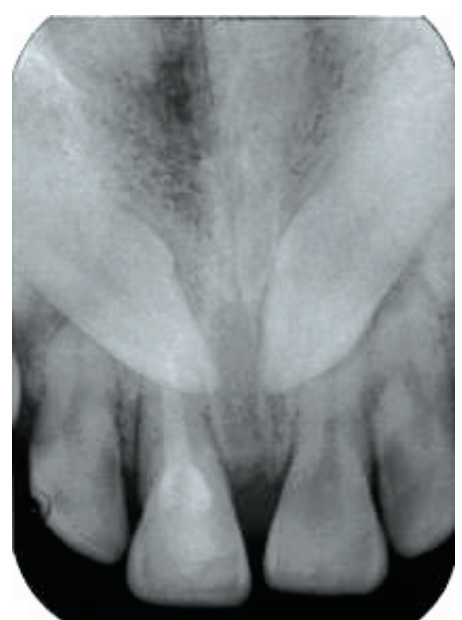

Figure 8. Radiographic examination after 12 month. 
bonds to dentin enhance this option. ${ }^{8,9}$ In this case, a glass fiber post was used to retain the coronal segment and reduce the stress on the luting material. The post interlocks the two separate fragments and minimizes the stress on the remaining tooth structure. ${ }^{7,10}$

The re-attachment of a tooth fragment is a viable technique that restores function and esthetics with a very conservative approach, but for each trauma case should be attempted to restore on an individual basis.

\section{REFERENCES}

1. Bondemark L, Kurol J, Hallonsten AL, Andreasen JO. Attractive magnets for orthodontic extrusion of crownroot fractured teeth. Am J Orthod Dentofacial Orthop 1997;112:187-193.

2. Andreasen JO, Andreasen FM. Essentials of traumatic injuries to the teeth, 1st edn. Copenhagen: Munksgaard; 1991. p. 47-62.

3. Wang Z, Heffernan M, Vann WF Jr. Management of a complicated crown-root fracture in a young permanent incisor using intentional replantation. Dent Traumatol 2008;24:100-103.

4. Baratieri LN, Monteiro S, De Andrada MAC. Tooth fracture reattachment: case reports. Quintessence Int 1990;21:261270 .

5. Arhun N, Ungor M. Re-attachment of a fractured tooth: a case report. Dent Traumatol 2007;23:322-326.

6. Zorba YO, Ozcan E. Reattachment of coronal fragment using fiber-reinforced post: a case report. Eur J Dent 2007;1:174178.

7. Trushkowsky RD. Esthetic, biologic and restorative considerations in coronal segment reattachment for a fractured tooth: a clinical report. J Prosthet Dent 1998;79:115-119.

8. Baratieri LN, Monteiro S Jr, de Albuquerque FM, Vieira LC, de Andrada MA, de Melo Filho TC. Reattachment of a tooth fragment with a new adhesive system: a case report. Quintessence Int 1994;25:91-96.

9. Fidel SR, Sassone L, Alvares GR, Guimarães RP, Fidel RA. Use of glass fiber post and composite resin in restoration of a vertical fractured tooth. Dent Traumatol 2006;22:337339.

10. Greenfeld RS, Roydhouse RH, Marshall FJ, Schoner B. A comparison of two post systems under applied compressive-shear loads. J Prosthet Dent 1989;61:17-24. 